University of New Hampshire

University of New Hampshire Scholars' Repository

Jackson Estuarine Laboratory

Institute for the Study of Earth, Oceans, and

Space (EOS)

$10-1-2002$

\title{
Neural Correlates of Swimming Behavior in Melibe leonina
}

Winsor $\mathrm{H}$. Watson III

University of New Hampshire, Durham, win.watson@unh.edu

James M. Newcomb

University of New Hampshire, Durham

Stuart Thompson

Stanford University

Follow this and additional works at: https://scholars.unh.edu/jel

\section{Recommended Citation}

Watson, W. H. III, J. A. Newcomb and S. Thompson. 2002. Neural correlates of swimming behavior in Melibe leonina. Biol. Bull. 203: 152-160. https://doi.org/10.2307/1543384

This Article is brought to you for free and open access by the Institute for the Study of Earth, Oceans, and Space (EOS) at University of New Hampshire Scholars' Repository. It has been accepted for inclusion in Jackson Estuarine Laboratory by an authorized administrator of University of New Hampshire Scholars' Repository. For more information, please contact Scholarly.Communication@unh.edu. 


\title{
Neural Correlates of Swimming Behavior in Melibe leonina
}

\author{
WINSOR H. WATSON III ${ }^{1,2, *}$, JAMES M. NEWCOMB ${ }^{1,2, \downarrow}$, AND STUART THOMPSON ${ }^{2,3}$ \\ ${ }^{1}$ Zoology Department and Center for Marine Biology, University of New Hampshire, Durham, New \\ Hampshire 03824; ${ }^{2}$ Friday Harbor Laboratories of the University of Washington, Friday Harbor, \\ Washington 98250; and ${ }^{3}$ Hopkins Marine Station, Stanford University, Pacific Grove, California 93950
}

\begin{abstract}
The nudibranch Melibe leonina swims by rhythmically bending from side to side at a frequency of 1 cycle every 2-4 s. The objective of this study was to locate putative swim motoneurons (pSMNs) that drive these lateral flexions and determine if swimming in this species is produced by a swim central pattern generator (sCPG). In the first set of experiments, intracellular recordings were obtained from pSMNs in semi-intact, swimming animals. About 10-14 pSMNs were identified on the dorsal surface of each pedal ganglion and 4-7 on the ventral side. In general, the pSMNs in a given pedal ganglion fired synchronously and caused the animal to flex in that direction, whereas the pSMNs in the opposite pedal ganglion fired in anti-phase. When swimming stopped, so did rhythmic pSMN bursting; when swimming commenced, pSMNs resumed bursting. In the second series of experiments, intracellular recordings were obtained from pSMNs in isolated brains that spontaneously expressed the swim motor program. The pattern of activity recorded from pSMNs in isolated brains was very similar to the bursting pattern obtained from the same pSMNs in semi-intact animals, indicating that the SCPG can produce the swim rhythm in the absence of sensory feedback. Exposing the brain to light or cutting the pedal-pedal connectives inhibited fictive swimming in the isolated brain. The pSMNs do not appear to participate in the SCPG. Rather, they received rhythmic excitatory and inhibitory synaptic input from interneurons that probably comprise the $\mathrm{SCPG}$ circuit.
\end{abstract}

Received 7 November 2001; accepted 28 June 2002.

* To whom correspondence should be addressed. E-mail: win@unh.edu

\$Current address: Department of Biology, Georgia State University, PO Box 4010, Atlanta, GA 30302-4010.

Abbreviations: IBI, interburst interval; pSMN, putative swim motoneuron; sCPC, swim central pattern generator; STG, stomatogastric ganglion.

\section{Introduction}

Investigations of rhythmic behaviors, such as feeding, swimming, and walking, have significantly contributed to our understanding of the neural mechanisms underlying stereotyped behaviors (Grillner and Wallen, 1985; Getting, 1989; Pearson, 1993; Marder and Calabrese, 1996). Invertebrate preparations have been particularly useful because they often have large, identifiable neurons that are accessible to intracellular investigation in both isolated ganglia and in semi-intact preparations (Lukowiak, 1991; Calabrese and De Schutter, 1992). The general view that has emerged from these studies is that rhythmic fixed-action patterns are produced by central pattern generators (CPGs) that are modulated and controlled by sensory inputs and neurohormones (Delcomyn, 1980; McCrohan, 1988; Getting, 1989; HarrisWarrick and Marder, 1991; Pearson, 1993; Marder and Calabrese, 1996).

The rhythmic swimming behavior of marine molluscs has been studied extensively since the classic investigations of Willows, Getting, Hoyle, Dorsett, and their colleagues on the nudibranch Tritonia diomedea (Willows, 1967; Willows and Hoyle, 1969; Willows et al., 1973; Dorsett et al., 1973; Getting et al., 1980; Hume et al., 1982). By developing a method for recording from identifiable neurons in swimming animals, they were able to identify the motoneurons and the network of interneurons responsible for generating the dorsal-ventral swimming movements. Subsequent work yielded many additional features of the swim CPG and showed that the rhythm depended on complex synaptic interactions between neurons, as well as on the intrinsic properties of a subset of the CPG neurons (Getting, 1983a, b). More recently, Katz and Frost identified cells that trigger swimming, and neuromodulators, such as serotonin, that 
alter the pattern produced by the swim CPG (Katz and Frost, 1995, 1996).

Whereas Tritonia swims using dorsal-ventral flexions of its entire body, Clione limacina, a pteropod mollusc, swims almost continuously by beating two "wings." The swim CPG consists of two groups of about 10 interneurons that reciprocally inhibit each other (Satterlie, 1985). Although the basic neural mechanisms underlying swimming appear to be simple, the actual swimming behavior of Clione is quite complex, and during the last decade Satterlie, Norekian, Arshavsky, and their colleagues have contributed a great deal to our understanding of pattern generator reconfiguration, the neural basis of behavioral switching, and modulation of neural networks (Arshavsky et al., 1985a, b; Huang and Satterlie, 1990; Satterlie, 1991; Satterlie and Norekian, 1996).

In comparison to our knowledge about Tritonia and Clione, our understanding of the neural basis of swimming in many other marine molluscs is more limited. Of the 47 swimming molluscs identified by Farmer (1970), electrophysiological investigations have been conducted on only three species in addition to Tritonia and Clione: Pleurobranchaea (Jing and Gillette, 1995, 1999); Aplysia brasiliana (von der Porten et al., 1982; McPherson and Blankenship, 1991a, b); and Melibe leonina (Watson et al., 2001). In these species, although the swim motoneurons and some critical elements of the CPG have been investigated, the neural circuits underlying swimming have not been elucidated in the detail that exists for both Tritonia and Clione.

The swimming behavior of the nudibranch Melibe leonina has been described in several publications (Agersborg, 1921; Hurst, 1968; Ajeska and Nybakken, 1976; Page, 1993; Watson et al., 2001), most recently in the accompanying manuscript (Lawrence and Watson, 2002). Melibe uses slow, rhythmic lateral flexions of its body wall to propel itself through the water. Although Melibe often swims spontaneously, a bout of swimming can also be elicited by contact with a predatory sea star (Pycnopodia). Behavioral analyses and preliminary intracellular recordings from semi-intact specimens of Melibe (Hurst, 1968; Thompson, unpubl. data), indicate that swimming is probably produced by a CPG. To expand upon our current knowledge of the neural basis of swimming in marine molluscs, and perhaps reveal certain common principles of neural organization through comparison with other wellstudied species, we undertook a neurophysiological investigation of swimming behavior in Melibe. In this paper, we characterize the activity of putative swim motoneurons (pSMNs) that give rise to swimming movements in semiintact specimens and to fictive swimming in isolated brains (fused cerebral-pleural-pedal ganglia). These studies demonstrate that swimming in Melibe is a highly stereotyped fixed-action pattern that is likely produced by a sCPG that rhythmically drives the pSMNs responsible for causing the alternating lateral flexions characteristic of the behavior.

\section{Materials and Methods}

\section{Animals}

Specimens of Melibe leonina (Gould, 1852) were collected by scuba in eelgrass beds near the University of Washington's Friday Harbor Laboratories, Friday Harbor, Washington. Specimens were maintained in flow-through seawater tables at $11-15^{\circ} \mathrm{C}$. Some animals were shipped to the Zoology Department, University of New Hampshire, Durham, New Hampshire, and held at $11-15{ }^{\circ} \mathrm{C}$ in a recirculating seawater aquarium. In general, animals held at Friday Harbor ate small zooplankton that were not filtered out of the seawater system, as well as organisms associated with eelgrass blades in the sea tables. The diet of specimens in the New Hampshire laboratory aquariums was similar and was supplemented with cultured Artemia once each week.

\section{Lucifer yellow injections of pSMNs}

Lucifer yellow (5\% solution in $0.15 M$ lithium chloride) was injected into putative swim motoneurons by passing 0.5-s, 10-nA hyperpolarizing current pulses, at a 50\% duty cycle, for $20 \mathrm{~min}$. Brains with injected cells were fixed overnight in $0.1 \mathrm{M}$ phosphate-buffered saline (PBS) with $4 \%$ paraformaldehyde at $4{ }^{\circ} \mathrm{C}$. Preparations were rinsed with PBS (four changes in $1 \mathrm{~h}$ ), dehydrated, cleared in xylene and methyl salicylate, and mounted in DPX (Fluka). They were then viewed and photographed using either a Nikon or Zeiss epifluorescent microscope or a BioRad confocal microscope.

\section{Cobalt chloride backfilling}

Pedal nerves were backfilled with $500 \mathrm{mM} \mathrm{CoCl} 2$, using a procedure modified from Croll (1986). Brains were removed, leaving the nerve that was to be backfilled as long as possible and cutting all other nerve roots close to the brain. The brain was placed inside a small petroleum jelly well filled with seawater, and the nerve to be filled was placed across one of the walls of the well, into a pool of 500 $\mathrm{mM} \mathrm{CoCl}{ }_{2}$. After incubating in the refrigerator for $24 \mathrm{~h}$, the brain was removed and washed four times, for 5 min each, in seawater. The cobalt was then precipitated by adding a few drops of ammonium sulfide to the seawater and incubating the brain in that solution for $5 \mathrm{~min}$. The brain was then fixed for $1 \mathrm{~h}$ with Carnoy's fixative, cleared, dehydrated, and mounted in Permount for viewing. 


\section{Intact animal preparations}

A semi-intact, whole-animal preparation similar to that developed by Willows (1967) for investigating swimming in Tritonia was modified for use with Melibe. After a small slit was made in the dorsal integument just over the brain, animals were suspended in a recording chamber by threads attached to the integument with small pins. Pins were inserted around the border of the slit to hold it open, while at the same time stabilizing that portion of the specimen. A small platform coated with wax and attached to a metal rod was slipped under the brain and held in place with a micromanipulator. The thick sheath covering the brain was opened and pinned to the wax platform to stabilize the brain, but the very thin sheath holding the neuronal cell bodies in place was left intact. The entire chamber was continuously perfused with natural seawater at $11-15{ }^{\circ} \mathrm{C}$.

Swimming movements were monitored by two methods. In one, a silk suture was tied to the posterior tip of the animal's body and connected to a lever arm bearing a flag. Swimming caused the flag to move and partially shield a photocell that was illuminated from above. This yielded a voltage output from the photocell that was maximal at peak right flexion and minimal at peak left flexion. The other approach was to direct a small Photonic sensor at the posterior region of the animal. This sensor transmitted light and recorded the reflected light, yielding a maximal signal when the body bent towards it and minimal output during flexion in the other direction. Although neither measured the strength and magnitude of movements with complete accuracy, these methods were adequate for recording the relative amplitude and frequency of swimming contractions.

\section{Isolated brain preparations}

The brain, which consists of the fused cerebral, pleural, and pedal ganglia, was removed by cutting all nerve roots except the three connectives that pass around the esophagus. The esophagus was then removed, taking care not to cut the pedal-pedal and para-pedal connectives that run parallel to the buccal-buccal connectives (Trimarchi and Watson, 1992). The isolated brain was pinned in a small $(2-5 \mathrm{ml})$ Sylgard-lined acrylic plastic chamber that was maintained at $11-15{ }^{\circ} \mathrm{C}$ by circulating ambient seawater or antifreeze, from a temperature-controlled water bath, through an aluminum cooling jacket surrounding the chamber. The brain was continuously perfused with cool seawater or with artificial saline containing (in $\mathrm{mM}$ ): $470 \mathrm{NaCl}, 10 \mathrm{KCl}, 10$ $\mathrm{CaCl}_{2}, 50 \mathrm{MgCl}_{2}, 10$ HEPES (pH 8).

\section{Electrophysiology}

A focal extracellular recording method was used to identify neurons that might participate in swimming. An extracellular electrode consisting of a pair of pipets with $20-50$ $\mu \mathrm{m}$ diameter tips was positioned over the soma of a neuron of interest, and the somatic currents associated with action potentials were measured by pressing one pipet tip against the sheath just over the cell body. A systematic survey of the dorsal and ventral surfaces of more than 30 preparations made it possible to tentatively map the position of neurons whose firing was correlated with swimming activity.

Intracellular recordings were obtained using 20-40 megohm electrodes filled with $3 \mathrm{M} \mathrm{KCl}$ or $2 M$ potassium acetate. Current was injected using bridge-circuits to reduce stimulus artifacts. Permanent records were produced with Gould/Brush or Astro-Med chart recorders. In some experiments, a digital oscilloscope was used to generate averages or to produce interval histograms.

\section{Results}

\section{Overview of Melibe brain anatomy and location of putative swim motoneurons}

The brain of Melibe leonina has been described and illustrated by Hurst (1968), Trimarchi and Watson (1992), and most recently Watson et al. (2001) and Newcomb and Watson (2001). It consists of fused cerebral-pleural ganglia connected to a pair of lateral pedal ganglia (Fig. 1A). A pair of pedal-pedal connectives encircle the esophagus and link the two pedal ganglia. Finally, the eyes and statocysts are prominent features on the dorsal surface of the brain.

Two methods were used to establish the approximate locations of neurons involved in the swimming behavior of Melibe. First, an extracellular electrode was used to scan the surface of the brain in a swimming animal and identify those neurons whose bursting pattern correlated with swimming movements. In five preparations, it was estimated that between 10 and 14 pSMNs exist on the dorsal surface of each pedal ganglion and from 4 to 7 on the ventral surface. A few additional neurons that fired with the same basic pattern as the pSMNs in the pedal ganglia were found in the cerebral-pleural ganglia. The second approach was to backfill pedal nerves with $\mathrm{CoCl}_{2}$. Although this was successful in revealing pSMNs, many non-pSMN cell bodies also stained; thus this method did not help focus subsequent intracellular investigations on a specific area of the pedal ganglia.

The anatomical properties of swim motoneurons were characterized in more than 20 neurons that were filled with Lucifer yellow after their electrophysiological properties were characterized. In all cases, these cells sent processes out one or more of the pedal nerves, typically PD4 and PD5 (Fig. 1B). They never projected to the cerebral-pleural ganglia or through the pedal-pedal connectives to the opposite pedal ganglia. Although we were unable to trace pSMN axons to their targets, we could determine the general area innervated by these nerves. Nerve PD4 bifurcated into an anterior branch and a posterior branch. The anterior branch 

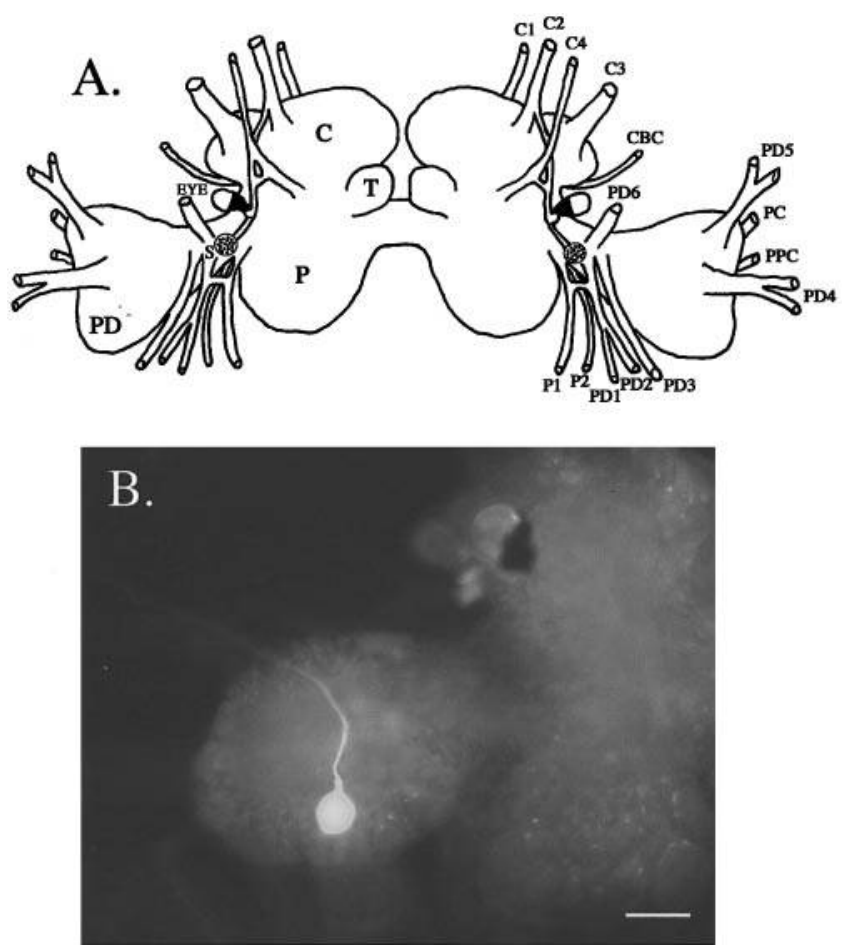

Figure 1. Anatomy of the brain and putative swim motoneurons in Melibe leonina. (A) Drawing of the brain. The two fused ganglia that constitute most of the brain are the cerebral $(\mathrm{C})$ and pleural $(\mathrm{P})$ ganglia (also referred to jointly as the cerebro-pleural ganglia). Near the large commissure that connects both halves of the brain are the paired tentacular lobes (T). The left and right pedal ganglia (PD) are lateral to the cerebropleural ganglia. Note that the eyes are located close to the brain, as are the statocysts (S), which are nestled between the pleural and pedal ganglia. The abbreviations for all the nerves are as follows: $\mathrm{C} 1=$ cerebral nerve, $\mathrm{C} 2=$ cerebral nerve $2, \mathrm{C} 3=$ cerebral nerve $3, \mathrm{C} 4=$ cerebral nerve $4, \mathrm{CBC}=$ cerebro-buccal connective, $\mathrm{P} 1=$ pleural nerve $1, \mathrm{P} 2=$ pleural nerve 2 , $\mathrm{PC}=$ pedal connective, $\mathrm{PD} 1=$ pedal nerve $1, \mathrm{PD} 2=$ pedal nerve 2 , PD3 $=$ pedal nerve 3, PD4 $=$ pedal nerve 4, PD5 $=$ pedal nerve 5, PD6 $=$ pedal nerve $6, \mathrm{PPC}=$ parapedal connective. (B) Photomicrograph of a swim motoneuron in the left pedal ganglion that was injected with Lucifer yellow. It projects out nerve PD5, which innervates portions of the foot and body wall. Scale bar $=100 \mu \mathrm{m}$.

innervated the anterior region of the foot and body wall, and the posterior branch projected to the middle region of the foot and body wall, as well as the ovotestes. Pedal nerve 5 projected to the neck region (anterior branch) and the most anterior $1 \mathrm{~cm}$ of the foot. The remainder of the pedal nerves (1-3) projected to portions of the gut and body wall.

\section{Activity of putative swim motoneurons in intact animals}

When semi-intact specimens of Melibe were swimming, the pSMNs in each pedal ganglia expressed a strong, rhythmic firing pattern (Fig. 2). Each burst preceded a bending of the body wall, with activity of neurons in a given pedal ganglion correlated with bending of the body in the ipsilateral direction (Fig. 2). The pattern of rhythmic bursting that characterized swimming was observed only during swimming behavior, and swimming was always closely coupled to rhythmic bursting of certain pedal neurons. When animals paused, with the body bent in one direction, the ipsilateral pSMNs were tonically active, while those on the opposite side were inhibited (Fig. 2). Stimulation of these same neurons in quiescent animals gave rise to small contractions in discrete body wall muscles and movements similar to the ones observed during portions of swimming activity. These observations, taken together with the anatomy of these neurons, suggest that they are swim motoneurons. However, until more definitive anatomical studies are carried out to determine if they directly innervate body wall musculature, we will continue to refer to them as putative SMNs.

\section{Recordings from isolated brains}

Isolated brains spontaneously expressed a swim motor pattern that was nearly identical to the pattern recorded from pSMNs in intact swimming individuals (Fig. 3). Putative SMNs fired in strong bursts, triggered by periodic waves of depolarization that alternated with periods of intense hyperpolarization. In an examination of recordings from 10 brains, the average cycle period, from the beginning of one burst to the beginning of the next, was $3.26 \pm 0.18 \mathrm{~s}$, while the average burst duration was $1.54 \pm 0.14 \mathrm{~s}$ and the interburst interval (IBI) was $1.72 \pm 0.13 \mathrm{~s}$. These figures correlate very well with similar parameters recorded from five semi-intact preparations $($ cycle $=3.40 \pm 0.20$, burst $=$ $1.84 \pm 0.16 \mathrm{~s}, \mathrm{IBI}=1.57 \pm 0.11 \mathrm{~s} ; n=5$ ) and to a lesser extent with data from freely swimming animals (mean swim cycle $=2.7 \pm 0.2 \mathrm{~s}$; see Lawrence and Watson, 2002).

Isolated brains spontaneously expressed the swim motor program as soon as they were excised from the animal. Preparations with both the pedal-pedal connectives cut were unable to generate a swim pattern, suggesting that critical components of the swim CPG interact through this pathway. In general, preparations were more likely to express the swim pattern in the dark, or in dim light, than during bright illumination. The eyes of Melibe are located on the brain, and it is likely that the inhibitory effect of light is mediated by the eyes (Lawrence, 1997).

As demonstrated in semi-intact animals, pSMNs in the same pedal ganglion are synergistic, whereas those in opposite pedal ganglia are out of phase with each other (Fig. $3 \mathrm{~A})$. However, within the same ganglion, the pSMNs do not all fire simultaneously. Rather, different cells fire during slightly different phases of the cycle. At least one cell in each pedal ganglion fires out of phase with the rest of the cells in the ganglion (Fig. 3B) and in phase with cells in the opposite pedal ganglion (Fig. 3C). The exact role of this cell is not fully understood, although in semi-intact preparations direct stimulation of these cells causes the anterior of the 


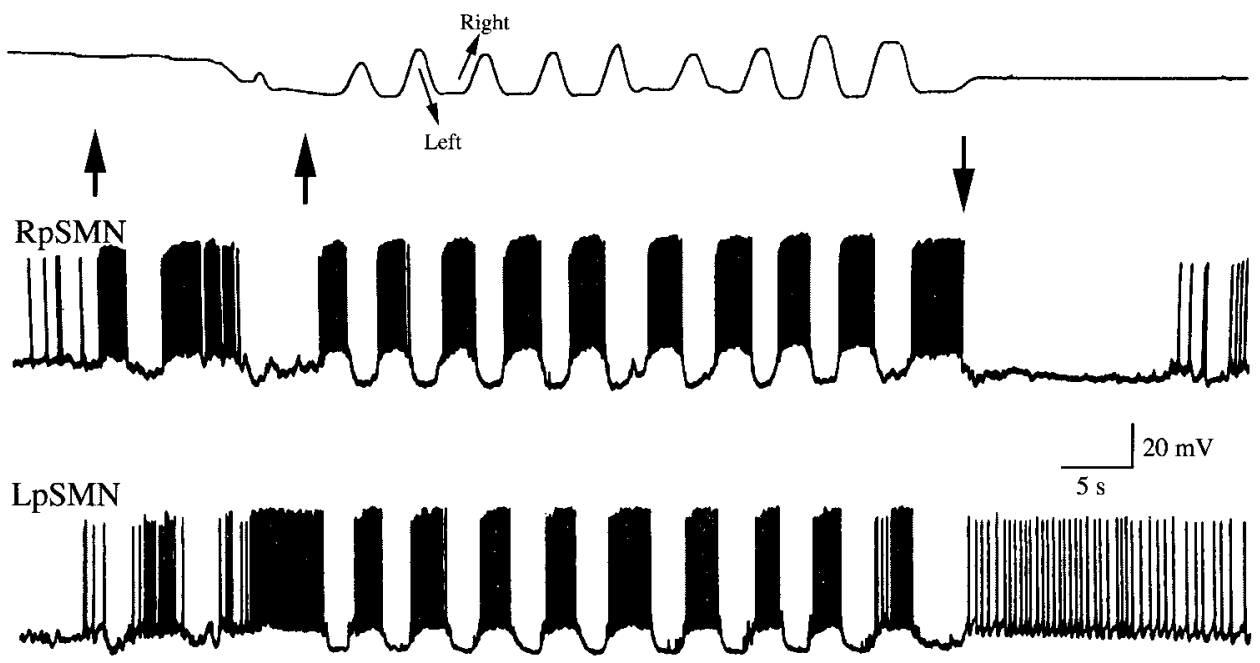

Figure 2. Relationship between putative swim motoneuron activity and swimming movements in Melibe. Swimming and associated left pedal and right pedal pSMN bursting activity were initiated by dislodging the foot of the animal from the substrate and terminated when the substrate was brought back in contact with the foot. The two up arrows indicate the beginning and end of the time during which the animal was slowly withdrawing from the substate, and the down arrow indicates when swimming stopped and the animal reattached to the substrate. The upper trace illustrates the output of a photocell that was used to monitor swimming movements. Output of the photocell was maximal when the animals were flexed to the right. Bursting of the pSMNs occurred before slow bending in the ipsilateral direction. When swimming stopped, the left pSMN remained tonically active, at a frequency that was too low to cause much flexion, while the right SMN stopped firing.

foot to be pulled to the ipsilateral side, a movement that is recognized as one of the early events in contralateral bending.

\section{Interneurons drive the putative swim motoneurons}

The swim pattern appears to be imposed on the pSMNs by the interneurons that generate the pattern (Watson et al., 2001; Thompson and Watson, unpubl. data). When individual pSMNs are either hyperpolarized below threshold or depolarized to elicit continuous spiking, the overall swimming pattern is not altered in either intact animals or in isolated brains (Fig. 4). Furthermore, no evidence for synaptic interactions between pSMNs was obtained during several different types of experiments. In the first, $>70$ pairs of pSMNs were impaled in quiescent, non-swimming preparations, and action potentials were elicited in one while searching for constant latency PSPs in the other. In the second series of experiments, one cell in a pair was slightly depolarized so that it fired tonically at a frequency of between 0.25 and $1 \mathrm{~Hz}$, and then the other neuron was depolarized so that it produced $5 \mathrm{~s}$ bursts. No change was observed in the firing frequency of the tonically firing neuron in any of the 48 experiments performed in this manner, using both antagonistic and synergistic pairs of pSMNs. Finally, no evidence of electrical coupling was observed in $>20$ pairs of pSMNs. Thus, based on these results, it is very unlikely that the pSMNs influence each other or participate in production of the swim motor program.
The role of putative swim motoneurons in other behaviors

Many of the pSMNs that normally produce bursts of spikes during swimming are active in a different pattern, with variable frequencies, during the movements associated with other behaviors. For example, during crawling, pSMNs are weakly activated while the animal is moving directly forward, and during turning they are active irregularly at frequencies correlated with the direction and vigor of the right or left turning. Figure 5 shows activity recorded from two pSMNs in the right pedal ganglion during a turn to the right that was elicited with a touch to the left body wall. Following the touch, the cells received excitatory synaptic drive, which gave rise to bursts of spikes and subsequent turning of the animal to the right. In contrast, during the crumpling response, when animals undergo bilateral contraction of the body wall, left and right pedal pSMNs fire at the same time. Thus, it appears as if the pSMNs are involved in a number of different behaviors that involve movements of the lateral body wall, and their pattern of activity during these different behaviors is primarily dictated by their synaptic input and not by connections between the pSMNs.

\section{Discussion}

The results of this study suggest that the swimming behavior of Melibe leonina is produced by a central pattern generator (CPG) capable of expressing a swimming motor 

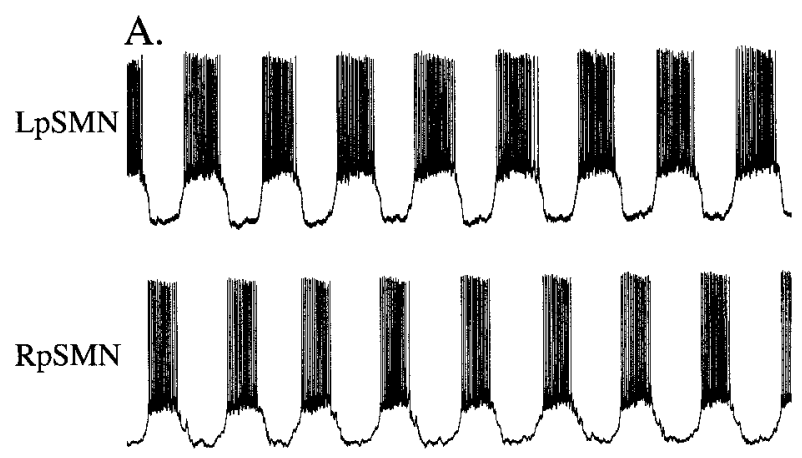

B.
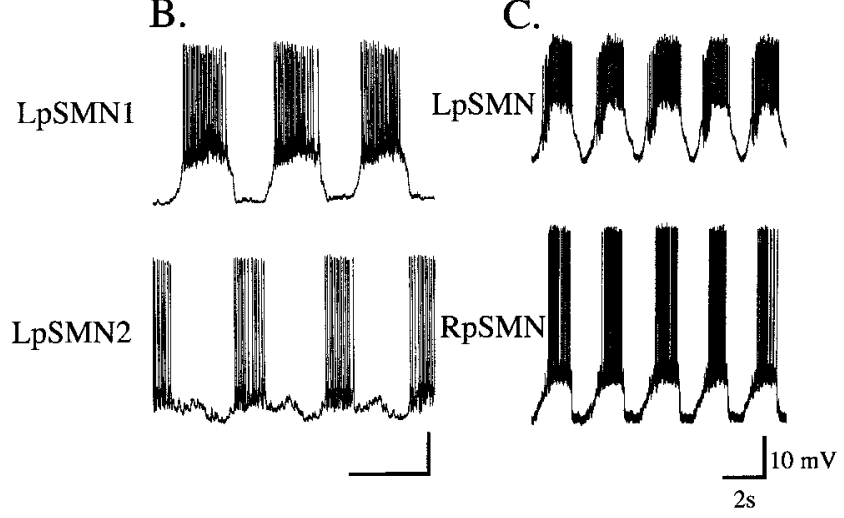

Figure 3. Swim motor program recorded from spontaneously active pedal motoneurons in the isolated Melibe brain. (A) Most putative swim motoneurons in the left (LpSMN, top) and right (RpSMN, bottom) pedal ganglia fire out of phase with each other, and thus produce the rhythmic lateral bending movements that characterize swimming. (B, C) All pSMNs on a given side do not fire with the same pattern. (B) Recordings from two pSMNs $(1,2)$ in the same pedal ganglia, in an isolated brain, that fire out of phase. (C) Recordings in a different isolated brain, obtained from two pSMNs in opposite pedal ganglia that fired in phase with each other. The right pSMN (RpSMN) is out of phase with the rest of the pSMNs in the right pedal ganglion. Scale markers $=2 \mathrm{~s}$ and $10 \mathrm{mV}$ for all panels.

program in the absence of sensory feedback. When recording intracellularly from putative swim motoneurons (pSMNs) in the pedal ganglia of semi-intact animals, we found that swimming behavior was very closely correlated with pSMN bursting. When swimming started, bursting commenced; when swimming stopped, bursting stopped. Stimulation of these same pSMNs caused bending of the animal in the ipsilateral direction, and Lucifer yellow injections of these neurons revealed axons projecting out pedal nerves toward the lateral body musculature. Furthermore, it was possible to record from these same pSMNs in isolated brains spontaneously expressing the swim motor program, and they produced bursts in a pattern that was nearly identical to the activity they expressed during swimming in semi-intact animals. In intact animals, contact of the foot with a substrate, such as an eelgrass blade, normally suppressed swimming. When the brain was excised, this inhibitory input was apparently eliminated, causing spontaneous expression of the swim motor program. In fact, isolated brains that were still attached to a piece of the anterior foot did not swim spontaneously. These data, taken together, suggest that swimming in Melibe is a rhythmic fixed-action pattern produced by a CPG.

Our study suggests the existence of sCPG that drives appropriate sets of pSMNs that, in turn, activate the body wall muscles that move this nudibranch in a series of lateral flexions. These pSMNs have very little influence on each other or the sCPG. Hyperpolarizing and depolarizing individual pSMNs does not influence the swimming behavior of semi-intact animals and has little impact on the fictive swim pattern produced by the isolated brain. Furthermore, there is no evidence of synaptic interactions, either chemical or electrical, between antagonistic or synergistic pairs of pSMNs (although on occasion we observed the type of subtle influence shown in Fig. 4B). This type of organization allows for the pedal motoneurons to fire in different patterns and thus participate in a wide variety of behaviors. For example, during an aversive crumpling response, both right
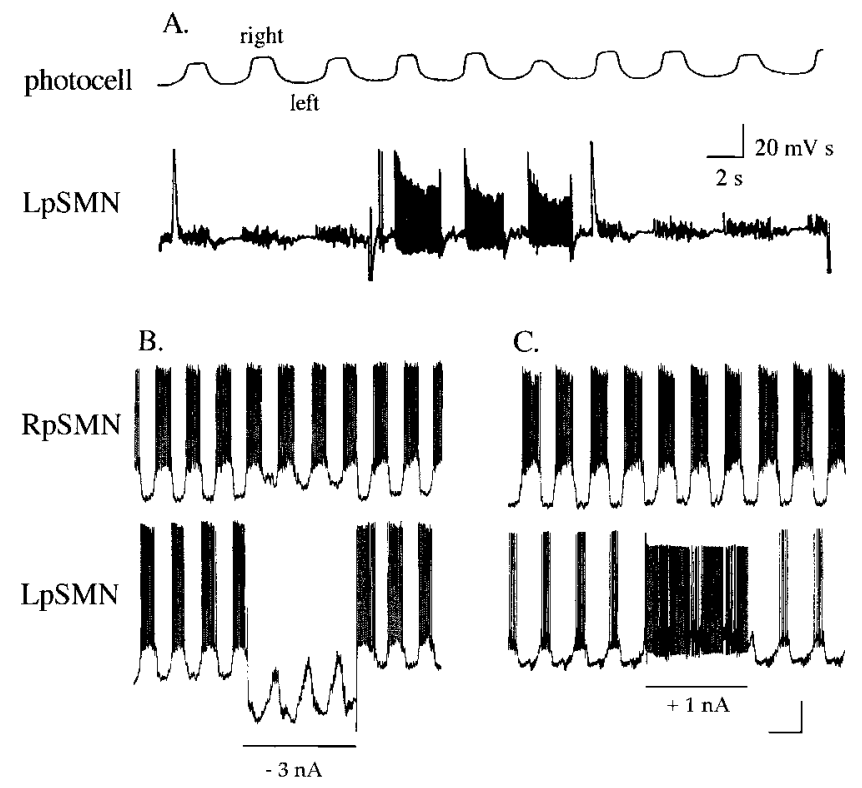

Figure 4. Depolarization and hyperpolarization of individual putative swim motoneurons have little influence on the swim motor program in intact animals (A) or in isolated brains (B, C). The records in panel A show the animal's movements (upper trace) and the activity recorded from a left pSMN during swimming (lower trace, AC coupled). At the beginning of the record, the neuron was strongly hyperpolarized for three cycles to prevent spiking despite excitatory input from the swim interneurons. It was then depolarized for three cycles to cause prolonged bursting, and hyperpolarized again. These alterations in the firing pattern had no effect on the ongoing swimming rhythm. The records shown in $\mathrm{B}$ and $\mathrm{C}$ are from two different isolated brains. Hyperpolarization (B) or depolarization (C) of a left pSMN (bottom) did not influence the swim pattern recorded from a RpSMN (top). However, in this example, strong hyperpolarization of the LpSMN did cause a slight depolarization of the RpSMN in the opposite pedal ganglion. This was not typical, and we do not know what pathways mediate this interaction. 

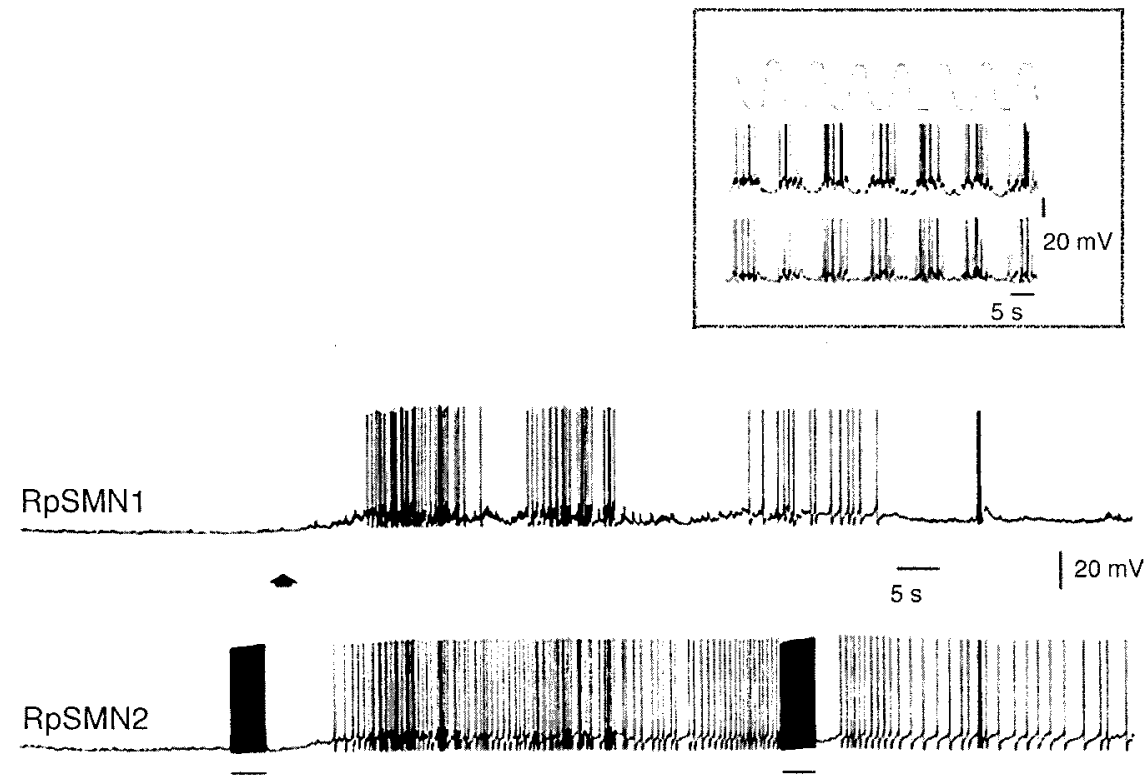

Figure 5. Activity of two putative swim motoneurons in the right pedal ganglion during a spontaneous turning movement to the right while the animal was crawling on a substrate. The turning movement was initiated by touching the contralateral body wall with a probe at the time marked by the arrow. The lower cell was depolarized with applied current so that it fired a burst of spikes before initiation of the turning movement and again during the movement (time of stimulation marked by bars). The stimulation had no effect on the activity recorded in the other pSMN. The insert shows bursting activity in the same two cells during swimming. The top trace is a monitor of movement, as in Figure 2, with movements to the right indicated by the trace going in the upward direction. In both figures the scale bars are $5 \mathrm{~s}$ and $20 \mathrm{mV}$.

and left pSMNs fire together rather than out of phase with each other (Thompson, unpubl. data); and during turning, ipsilateral motoneurons fire prolonged bursts together (Fig. 5). This type of sharing of motoneurons by different circuits is a common organizational theme that has been demonstrated in other swimming molluscs (Tritonia, Getting, 1989; Clione, Satterlie, 1991) as well as in many other species. However, it is not the only way that neural circuits driving rhythmic behaviors are organized. For example, in the stomatogastric ganglia (STG) of crustaceans, motoneurons have extensive synaptic interactions with each other and with interneurons (Miller and Selverston, 1985; Marder and Calabrese, 1996). Yet, they can participate in different motor outputs because a variety of neuroactive substances are capable of modulating the synaptic interactions between STG neurons, as well as the electrical properties of individual cells, thus pharmacologically creating transiently coherent neural networks (Harris-Warrick and Marder, 1991).

It is difficult to compare the neural basis of swimming in Melibe with the mechanisms underlying swimming in other opisthobranchs. In part, this is because, although the dominant form of swimming in opisthobranchs involves lateralbending movements (Farmer, 1970), little is known about the neural basis of this form of swimming. Of the species most thoroughly investigated in terms of neuroethology, Tritonia (both $T$. diomedea and T. hombergi) and Pleuro- branchaea swim using doral-ventral flexions, Clione flaps its wings, and Aplysia brasiliana flaps its parapodia. In Tritonia and Pleurobranchaea the sCPGs are located in the cerebral-pleural ganglia, and the sCPG drives motoneurons in the pedal ganglia (Willows, 1967; Getting et al., 1980; Satterlie, 1985; see Lukowiak, 1991; McPherson and Blankenship, 1991a, b; Jing and Gillette, 1995, 1999). In contrast, in Clione and Aplysia brasiliana, the swim CPG and swim motoneurons are both located in the pedal ganglia (von der Porten et al., 1982; Arshavsky et al., 1985a, b; Satterlie, 1985; Satterlie and Norekian, 1996). Interestingly, the sCPG in Melibe appears to be a hybrid of these two organizational schemes, with critical elements of the sCPG located in both the cerebral-pleural ganglia and the pedal ganglion, and motoneurons concentrated in the pedal ganglia (Watson et al., 2001; Thompson and Watson, unpubl. data). Melibe also differs from the aforementioned species in the way the pSMNs are arranged within the pedal ganglia. In Melibe, the right and left pSMNs are well segregated between the left and right pedal ganglia, with most pSMNs located on the dorsal surface of each ganglion. In contrast, in Tritonia, a dorsal-ventral swimmer, the dorsal and ventral swim motoneurons are located together in both pedal ganglia (Hume et al., 1982); and in Clione and Aplysia, which move their wings and parapodia in the dorsal-ventral direction, the motoneurons are also mixed in each pedal ganglia. 
Further investigations of the neural basis of swimming in molluscs, especially other lateral-bending species, are likely to reveal additional organizational principles that are common to a wide range of neural circuits underlying rhythmic behaviors such as swimming.

\section{Acknowledgments}

We thank all the people at the Friday Harbor Laboratories, particularly Dennis Willows, David Duggins, and Craig Staude, for being wonderful hosts and providing a great atmosphere for research. We also appreciate all the FHL and UNH students who contributed insights throughout the years. We greatly appreciate the efforts of $\mathrm{Cy}$, Sooz, Celia, Janis, Peter, David, and Cathy in collecting Melibe. This study was supported by Center for Marine Biology grants through the University of New Hampshire, a SICB Grant-in-Aid of Research to J.M.N., an NIH grant (R15NSOD3641101) to W.H.W., and an NSF grant (\#IBN9514421) to S.T. It is contribution number 385 of the Center for Marine Biology/Jackson Estuarine Laboratory series.

\section{Literature Cited}

Agersborg, H. P. v. W. K. 1921. Contributions to the knowledge of the nudibranchiate mollusk, Melibe leonina (Gould). Am. Nat. 55: 222253.

Ajeska, R. A., and J. Nybakken. 1976. Contributions to the biology of Melibe leonina (Gould, 1852) (Mollusca: Opisthobranchia). Veliger 19: 19-26.

Arshavsky, Yu. I., I. N. Beloozerova, G. N. Orlovsky, Yu. V. Panchin, and G. A. Pavlova. 1985a. Control of locomotion in marine mollusc Clione limacina. II. Rhythmic neurons of pedal ganglia. Exp. Brain Res. 58: 263-272.

Arshavsky, Yu. I., N. Beloozerova, G. N. Orlovsky, Yu. V. Panchin, and G. A. Pavlova. 1985b. Control of locomotion in marine mollusc Clione limacina. III. On the origin of locomotory rhythm. Exp. Brain Res. 58: 273-284.

Calabrese, R. L., and E. De Schutter. 1992. Motor-pattern-generating networks in invertebrates: modeling our way toward understanding. Trends Neurosci. 15: 439-444.

Croll, R. P. 1986. Modified cobalt staining and silver intensification techniques for use with whole-mount gastropod ganglion preparations. J. Neurobiol. 17: 569-576.

Delcomyn, F. 1980. Neural basis of rhythmic behavior in animals. $\underline{S c i-}$ ence 210: 492-498.

Dorsett, D. A., A. O. D. Willows, and G. Hoyle. 1973. The neuronal basis of behaviour in Tritonia. IV. The central origin of a fixed action pattern demonstrated in an isolated brain. J. Neurobiol. 4: 287-300.

Farmer, W. M. 1970. Swimming gastropods (Opisthobranchia and Prosobranchia). Veliger 13: 73-89.

Getting, P. A. 1983a. Central pattern generator mediating swimming in Tritonia. III. Intrinsic and synaptic mechanisms for delayed excitation. J. Neurophvsiol. 49: 1036-1050.

Getting, P. A. 1983b. Neural control of swimming in Tritonia. Pp. 89-128 in Neural Origin of Rhythmic Movements. Symposia of the Society for Experimental Biology 37, A. Roberts and B. L. Roberts, eds. Cambridge University Press, New York.

Getting, P. A. 1989. Emerging principles governing the operation of neural networks. Annu. Rev. Neurosci. 12: 185-204.

Getting, P. A., P. R. Lennard, and R. I. Hume. 1980. Central pattern generator mediating swimming in Tritonia. I. Identification and synaptic interactions. J. Neurophysiol. 44: 151-164.

Grillner, S., and P. Wallen. 1985. Central pattern generators for locomotion, with special reference to vertebrates. Annu Rev. Neurosci. 8: 233-261.

Harris-Warrick, R. M., and E. Marder. 1991. Modulation of neural networks for behavior. Апnи. Rev. Neurosci. 14: 39-57.

Huang, Z., and R. A. Satterlie. 1990. Neuronal mechanisms underlying behavioral switching in a pteropod mollusc. J. Comp. Physiol. A 166: 875-887.

Hume, R. I., P. A. Getting, and M. A. Del Beccaro. 1982. Motor organization of Tritonia swimming. I. Quantitative analysis of swim behavior and flexion neuron firing patterns. J. Neurophysiol. 47: 60 74

Hurst, A. 1968. The feeding mechanism and behaviour of the opisthobranch Melibe leonina. Symp. Zool. Soc. Lond. 22: 151-166.

Jing, J., and R. Gillette. 1995. Neuronal elements that mediate escape swimming and suppress feeding behavior in the predatory sea slug Pleurobranchaea. J. Neurophvsiol. 74: 1900-1910.

Jing, J., and R. Gillette. 1999. Central pattern generator for escape swimming in the notaspid sea slug Pleurobranchaea californica. J. Neurophysiol. 81: 654-667.

Katz, P. S., and W. N. Frost. 1995. Intrinsic neuromodulation in the Tritonia swim CPG: serotonin mediates both neuromodulation and neurotransmission by the dorsal swim interneurons. J. Neurophvsiol. 74: 2281-2294.

Katz, P. S., and W. N. Frost. 1996. Intrinsic neuromodulation: altering neuronal circuits from within. Trends in Neurosci. 19: 54-61.

Lawrence, K. A. 1997. Neuroethology of the swimming behavior of the Pacific nudibranch, Melibe leonina. Ph. D. dissertation, University of New Hampshire, Durham. 78 pp.

Lawrence, K. A., and W. H. Watson III. 2002. The swimming behavior of the nudibranch Melibe leonina. Biol. Bull. 203: 144-151.

Lukowiak, K. 1991. Central pattern generators: some principles learned from invertebrate model systems. J. Physiol. 85: 63-70.

Marder, E., and R. L. Calabrese. 1996. Principles of rhythmic motor pattern generation. Physiol. Rev. 76: 687-717.

McCrohan, C. R. 1988. Modification of central pattern generation in invertebrates. Comp. Biochem. Physiol. 90A: 17-22.

McPherson, D. R., and J. E. Blankenship. 1991a. Neural control of swimming in Aplysia brasiliana. I. Innervation of parapodial muscles by pedal ganglion motorneurons. J. Neurophvsiol. 66: 1338 1351.

McPherson, D. R., and J. E. Blankenship. 1991b. Neural control of swimming in Aplysia brasiliana. II. Organization of pedal motorneurons and parapodial motor fields. J. Neurophysiol. 66: 1352-1365.

Miller, J. P., and A. I. Selverston. 1985. Neural mechanisms for the production of the lobster pyloric motor pattern. Pp. 37-48 in Model Neural Networks and Behavior, A. I. Selverston, ed. Plenum Press, New York.

Newcomb, J. M., and W. H. Watson III. 2001. Identifiable nitrergic neurons in the central nervous system of the nudibranch Melibe leonina, localized with NADPH-diaphorase histochemistry and nitric oxide synthase immunoreactivity. J. Comp. Neurol. 437: 70-78.

Page, L. R. 1993. Development of behavior in juveniles of Melibe leonina (Gastropoda: Nudibranchia). Mar. Behav. Physiol. 22: 141161.

Pearson, K. G. 1993. Common principles of motor control in vertebrates and invertebrates. Апnи. Rev. Neurosci. 16: 265-297.

Satterlie, R. A. 1985. Reciprocal inhibition and postinhibitory rebound produce reverberation in a locomotor pattern generator. Science 229: 402-404.

Satterlie, R. A. 1991. Neural control of speed changes in an opisthobranch locomotory system. Biol. Bull. 180: 228-233. 
Satterlie, R. A., and T. P. Norekian. 1996. Modulation of swimming speed in the pteropod mollusc, Clione limacina: role of a compartmental serotonergic system. Invertebr. Neurosci. 2: 157-165.

Trimarchi, J., and W. H. Watson. 1992. The role of Melibe buccal ganglia in feeding behavior. Mar. Behav. Physiol. 19: 195-209.

von der Porten, K., D. W. Parsons, B. S. Rothman, and H. Pinsker. 1982. Swimming in Aplysia brasiliana: analysis of behavior and neuronal pathways. Behav. Neural Biol. 36: 1-23.

Watson, W. H., K. D. Lawrence, and J. M. Newcomb. 2001. Neuro- ethology of Melibe leonina swimming behavior. Am. Zool. 41: 10261035 .

Willows, A. O. D. 1967. Behavioral acts elicited by stimulation of single, identifiable brain cells. Science 157: 570-574.

Willows, A. O. D., and G. Hoyle. 1969. Neuronal network triggering a fixed action pattern. Science 166: 1549-1551.

Willows, A. O. D., D. A. Dorsett, and G. Hoyle. 1973. The neuronal basis of behavior in Tritonia. III. Neuronal mechanism of a fixed action pattern. J. Neurobiol. 4: 255-285. 